\title{
PERFORMANCE AND ECONOMIC SUITABILITY OF THREE FAST- GROWING BROILER STRAINS RAISED UNDER FARMING CONDITION IN BANGLADESH
}

\author{
M.A. Hossain ${ }^{*}$, K.B. Suvo² and M.M. Islam³ \\ Received 14 September 2011, Revised 19 October 2011, Accepted 25 December 2011, Published online 31 December 2011
}

\begin{abstract}
The performance and profitability of three commercial broiler strains reared under farming system were investigated in this study. Day-old broiler chicks $(n=156)$ of three different commercial strains (Hubbard classic, Cobb-500 and MPK) were assigned to three treatment groups in a completely randomized block design, each treatment replicated four times, 13 birds per replicate. The birds were reared from d1 to 35 days of age with similar housing, feeding and environmental management condition. Regarding to all parameters collected, live weight and body weight gain were higher $(\mathrm{P}<0.001)$ in $\mathrm{T}_{2}(\mathrm{Cobb}-500)$ group, while the birds of $T_{3}$ (MPK) group were the lowest. Birds of $T_{1}$ (Hubbard Classic) and $T_{2}$ (Cobb-500) strain group consumed higher $(\mathrm{P}<0.001)$ feeds, while the birds of $\mathrm{T}_{3}(\mathrm{MPK})$ had the lowest feed intake. Cobb-500 broiler strain achieved superior $(P<0.001) F C R$, while the birds of $T_{1}$ (Hubbard classic) strain group had poorer FCR. Liveability of the broiler strains was unaffected by all the treatment groups. Higher net profit and lower production cost observed in $T_{2}($ Cobb-500) group than those of other strains, although the difference between the treatment groups was similar. The highly significant measurements of live body weight, weight gain and better FCR values were recorded for Cobb-500 broiler strain, followed by Hubbard classic and MPK, respectively. In conclusion, Cobb-500 broiler strain is appeared to be the most economic to rear amongst the three broiler strains investigated here in response to their performance records.
\end{abstract}

Keywords: Broiler Performances, Strains, Cost Benefit Ratio

\footnotetext{
${ }^{1 \& 2}$ Department of Dairy \& Poultry Science, Chittagong Veterinary \& Animal Sciences University, Khulsi, Chittagong, Bangladesh; ${ }^{3}$ Department of Animal Science \& Nutrition; Chittagong Veterinary \& Animal Sciences University, Khulsi, Chittagong, Bangladesh.

*Corresponding author's email: mhossainmu@yahoo.com
}

Reviewed by Syed Md. Ehsanur Rahman, Bangladesh Agricultural University, Mymensingh, Bangladesh

\section{Introduction}

The global livestock industry currently employs 1.3 billion people and accounts for $40 \%$ of agricultural GDP (Steinfeld et al., 2006), and this industry is supplying one-third of humanity's protein intake across the world. Global meat production is projected to double by 2050 for its increasing demand and trade in livestock products (FAO, 2006). In addition to this, poultry industry as micro-livestock contributing meat, eggs and other food products, and is recognized as the most popular emerging industry in the world. The popularity of this industry is increasing day by day as it is supplying nutritious and healthy food items i.e meat and egg to the consumers. This industry provides the people with health security by supplying them with premium quality of meat and egg that can remove the malnutrition of the people and huge protein gap of the country. As a result, it is emerging as a commercial venture in the world, and is rapidly shaping-up into an attractive enterprise in response to the increasing demand of animal proteins (meat and egg), which are required for alleviating the malnutrition problem for the people.

However, today's broiler industry has undergone a tremendous development and expansion during the last couple of decades around the world. The body weight gain of the broiler strains has been markedly increased, and the feed utilization has been strongly improved with the advancement of new technology applied in poultry nutrition as well as in genetics. This progress in breeding and nutrition has resulted in broiler strains having higher performances today than ever before (Bogdangnov, 1990). 
Despite the tremendous growth and development of modern broiler strains all over the world, the inadequate supply of quality animal protein is still the main problem for the people of Bangladesh. This problem is being aggravated by the increasing trend of human population, and thus creating a heavy pressure on every form of food supply in Bangladesh. The expansion of commercial broiler production in Bangladesh has a great potential for the partial fulfillment of huge protein gap of the country. Broiler production is being raised by both large scale and small scale commercial entrepreneurs under farming conditions for fulfiling the protein need of the country. Many people are now being encouraged in this enterprise, as maximum return can be achieved shortly by investing minimum capital in broiler production (Sarker et al., 2001).

However, the greatest scientific and technological development of poultry industry in the last years demanded the evaluation of different commercial broiler strains, as well as different management techniques in order to improve production efficiency, and help them in proper decisionmaking at farming strategy for the commercial broiler strains. This assessment of the fastgrowing broiler strains is creating a constant force to increase the world-scale meat and egg production for human consumption.

Owing to the above consequences, the continuous effort of the breeding companies towards producing high quality broiler strains with improved production traits necessitates continuing evaluation of the selected broiler lines. The broiler breeder strains commonly used by the broiler industry in Bangladesh are Arbor Acres, Hub chicks, Ross, Starbro, Hubbard classic, Cobb500, MPK, Lohman, Hybro G and Hybro N (Latif, 1999). Furthermore, supply of day-old chicks in the most of the poultry farms of Bangladesh, is coming mainly from ten International Poultry Breeding Companies, either from imported parent stocks or from imported hatching eggs (Latif, 1998). However, various traits of these broiler strains such as production potentials, resistance to disease incidences, marketing age, consumer demand, meat quality, profitability, adaptability etc., may affect adversely the farmer's preference and profit margin of rearing these birds in the farming conditions of Bangladesh.

However, Bangladesh is a developing and tropical country where poultry industry is growing rapidly with raising numerous broiler strains under the farming management. The productivity and adaptability of these strains may vary significantly due to several environmental factors, for example, temperature, humidity and other incidences (diseases) which may put a great impact on the production potentials and survivability of these fast-growing broiler strains. In addition, climatic stresses can affect the production performance and adaptability of these strains (Sarker et al., 2001) to an extent. Fast-growing broiler strains may face extreme heat stresses when they are exposed to higher temperature environmental condition, and therefore, may be unsuitable for rearing them under tropical environmental management condition (Bohren et al., 1982) profitably. Furthermore, adverse environmental impact on broiler performance is noticed by previous several researchers (Baghel and Pradhan, 1989; Islam, 2000), which is responsible to reduce the weight gains, feed consumption, feed efficiency, adaptability and profitability of rearing these strains under hothumid and dry seasons than any other coldclimatic conditions.

However, information on the probable performance and managing of these strains is typically obtained from the literatures made available by the breeder companies. This information does not necessarily apply to regional environmental effects (Farran et al., 2000) of any particular country. Therefore, lack of adequate information on the fast-growing broiler strains retrieved from these breeder companies is still perceived a salient constraint to the speedy growth broiler industry in Bangladesh. In view of the above consideration, the present study was undertaken to compare the performances and economic suitability of three commercial broiler strains (Hubbard classic, Cobb-500 and MPK) reared under the farming condition in Bangladesh.

\section{Materials and Methods}

A total of 156 day-old broiler chicks (either sex) were collected from the purchasing outlets of three different breeding hatcheries in Bangladesh. The chicks were randomly allocated into three treatment groups $\left(\mathrm{T}_{1}, \mathrm{~T}_{2} \& \mathrm{~T}_{3}\right)$ having 52 chicks in each group. Each treatment had four replications of 13 birds. Three broiler strains such as Hubbard classic, Cobb-500 and MPK were collected from the different purchasing outlets located at different places in Bangladesh. The birds were reared at the broiler farm in Magura district, Bangladesh from d1 to 35 in the year of 2008.

A total of 12 floor-pens of equal size were set up in an open-sided house to accommodate the birds from $d 1$ to 35 days. Each pen contained a feeder and a drinker for proper feeding and drinking. Litter of wood shaving materials to a depth of $2 \mathrm{~cm}$ was spread on the floor of each pen to maintain a comfortable environment for the birds. Feeders were cleaned daily before supplying diets, and drinkers were washed 
weekly to maintain hygienic condition for the birds. The birds were brooded with a temperature of $35^{\circ} \mathrm{C}$ for the first two days only, and then this was reduced by 1 or $2{ }^{\circ} \mathrm{C}$ every 1 or 2 days until day 19 , when the temperature was set at $24{ }^{\circ} \mathrm{C}$ and this temperature was maintained until the end of the trial period.Continuous lighting was provided throughout the trial period. Feeds were provided in a pelleted form. Birds had free access to water and feed which were provided adlibitum throughout the trial period.

Commercial ready-made compound broiler feeds (pellet) were supplied the birds adlibitum throughout the trial period. The feeds were collected from the purchasing outlets of the Aftab Bohumukhi feed mill company. Birds were fed the starter diets from 0 to 21days, and the finisher diets were used for the rest of the trial period ( 22 to 35 days). The nutrient composition of the experimental feed was shown in Table 1. The nutrient composition of the experimental feeds used in this study appeared to be a bit different from the recommended levels prescribed by NRC (1994) for the broiler chickens. All the birds received the necessary vaccines against Newcastle disease, Infectious Bursal diseases and Infectious Bronchitis disease and medicines for disease protection. All dead birds were sent to the Veterinary Hospital of Chittagong Veterinary \& Animal Sciences University, Chittagong, for postmortem examination to identify the causes of death.

Table1. Nutrients composition of the diets

\begin{tabular}{lll}
\hline Nutrients & $\begin{array}{l}\text { Starter } \\
(0-21 \text { days })\end{array}$ & $\begin{array}{l}\text { Finisher } \\
\text { (22-35 days) }\end{array}$ \\
\hline ME(MJ /kg) & 13.66 & 14.2 \\
$\mathrm{CP}(\%)$ & 23.9 & 20.20 \\
$\mathrm{CF}(\%)$ & 4.7 & 4.8 \\
EE (\%) & 6.70 & 8.0 \\
Ca (\%) & 1.30 & 1.10 \\
Available P (\%) & 0.50 & 0.50 \\
DL-Methionine (\%) & 0.43 & 0.40 \\
Lysine (\%) & 1.05 & 0.66 \\
Threonine(\%) & 0.86 & 0.59 \\
Arginine (\%) & 1.80 & 1.13 \\
\hline
\end{tabular}

Source: Adapted from Roy et al., 2004 and Hossain et al., 2008.

\section{Data collection}

Birds were weighed individually before allocating them into the pens, then in group wise on 15, 23, 28 and 35 days of age to the end of trial. Live body weight (LBW) and feed intake were recorded on the same days. Mortality was recorded daily, while body weight and feed intake were recorded on 15, 23, 28 and 35 days of age for the calculation of body weight gain, and FCR corrected for mortality. Mortality of birds was recorded daily as and when it was occurred, and finally liveability of the birds was calculated from this by deduction. The experimental design followed for this experiment was a completely randomized block design.

Live weight gain (LWG), FCR and cost benefit ratio (CBR) were calculated by the following ways:

LWG = Achieved body weight of the birds (g) Initial body weight (g) of the birds

$$
\begin{aligned}
& \mathrm{FCR}=\frac{\text { Feed intake ( } \mathrm{g})}{\text { Body weight gainf( } \mathrm{E})} \\
& \mathrm{CBR}=\frac{\text { Total eogt of production per bird }}{\text { Net protit attained by each bird }}
\end{aligned}
$$

\section{Statistical Analysis}

Statistical analyses were performed using Minitab software (Minitab version 16, 2010). All recorded data were subjected to analysis using one-way ANOVA with strain as a factor. The significance of difference between means was determined by the Fisher's comparison test.

\section{Results}

\section{Live weight}

Changes in live body weight from day 1 to 35 are graphically presented below (Fig.1). Results of average live weight gain (ALG), feed intake, feed conversion ratio and liveability are also shown in Table 2. At 28 and 35 days of age, body weight differed significantly $(\mathrm{P}<0.001)$ between the strains. Cobb-500 birds recorded heavier body weight compared to Hubbard classic and MPK birds from 28 to 35 days of age. Final weight differed significantly $(\mathrm{P}<0.001)$ between the strains. Birds of Cobb-500 strain were the heaviest (1425.3g) at 35 days of age compared to Hubbard Classic (1375.8g) and MPK (1315.1g) strains.

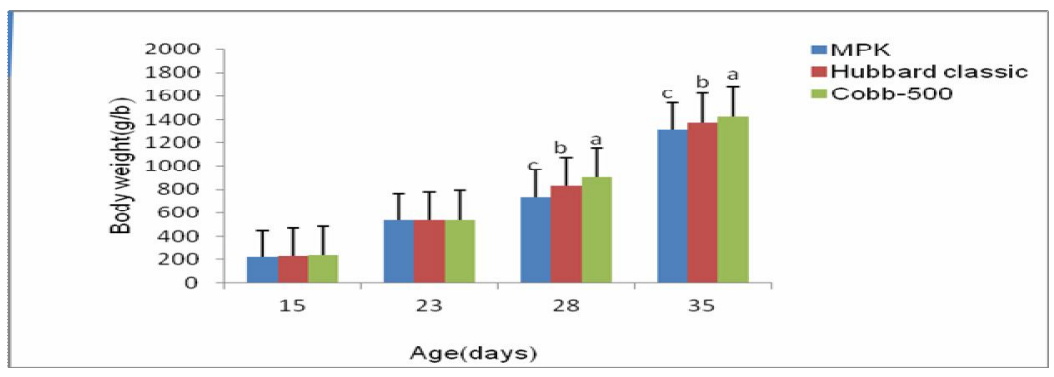

Fig. 1 Average live body weight ( $g$ ) of the strains from d15 to 35 days (values mean \pm SE) 


\section{Body weight gain}

Live weight gains of all the strains differed significantly $(\mathrm{P}<0.001)$ during $28^{\text {th }}$ and $35^{\text {th }}$ days of age. Average live weight gains upto 28th and $35^{\text {th }}$ days were significantly $(\mathrm{P}<0.001)$ greater for Cobb-500 strain compared to Hubbard and MPK strains. Body weight gains of the strains upto to $15^{\text {th }}$ and 23th days were not influenced $(\mathrm{P}>0.001)$ by all the treatment groups. Significantly $(\mathrm{P}<0.001)$ higher weight gain $(1385.3 \mathrm{~g})$ was observed on Cobb-500 birds, followed by $1335.3 \mathrm{~g}, 1274.6 \mathrm{~g}$ in Hubbard classic and MPK, respectively, during $35^{\text {th }}$ day.

Table 2. Performances of three commercial broiler strains from $15^{\text {th }}$ to 35 days of age

\begin{tabular}{|c|c|c|c|c|c|c|}
\hline \multirow{2}{*}{\multicolumn{2}{|c|}{ Age(day) }} & \multicolumn{3}{|c|}{ Treatments } & \multirow{2}{*}{$\begin{array}{l}\text { Pooled } \\
\text { SEM }\end{array}$} & \multirow{2}{*}{$\begin{array}{l}\text { Level of } \\
\text { significance }\end{array}$} \\
\hline & & $\mathrm{T}_{1}$ (Hubbard classic) & $\mathrm{T}_{2}(\mathrm{Cobb}-500)$ & $\mathrm{T}_{3}(\mathrm{MPK})$ & & \\
\hline \multirow{5}{*}{$\begin{array}{l}\text { Live-weight gain } \\
\text { (g/b) }\end{array}$} & $15^{\text {th }}$ & 190.5 & 185.7 & 179.9 & 3.29 & NS \\
\hline & 23th & 492.7 & 496.5 & 495.8 & 2.77 & NS \\
\hline & $28^{\text {th }}$ & $786.7 \mathrm{~b}$ & $860.3^{a}$ & $695.4^{c}$ & 3.00 & **** \\
\hline & $35^{\text {th }}$ & $1335.3^{b}$ & 1385.3a & $1274.6^{c}$ & 4.45 & **** \\
\hline & $15^{\text {th }}$ & 526.4 & 519.4 & 515.4 & 3.07 & NS \\
\hline \multirow{4}{*}{$\begin{array}{l}\text { Feed-intake } \\
(\mathrm{g} / \mathrm{b})\end{array}$} & 23th & $675.2^{c}$ & $980.8^{a b}$ & 985.9a & 1.35 & **** \\
\hline & $28^{\text {th }}$ & $1560.4^{\mathrm{b}}$ & $1580.6^{\mathrm{a}}$ & $1475.5^{c}$ & 1.98 & **** \\
\hline & $35^{\text {th }}$ & $2955.4^{\mathrm{a}}$ & $2855.4^{\mathrm{ab}}$ & $2783.0^{c}$ & 2.06 & **** \\
\hline & $15^{\text {th }}$ & 2.80 & 2.80 & 2.90 & 0.052 & NS \\
\hline \multirow[t]{4}{*}{ FCR } & 23th & $1.36^{\mathrm{b}}$ & $1.98 \mathrm{a}$ & $2.00^{a}$ & 0.012 & **** \\
\hline & $28^{\text {th }}$ & $1.98^{\mathrm{b}}$ & $1.84^{\mathrm{c}}$ & $2.12^{\mathrm{a}}$ & 0.009 & *** \\
\hline & $35^{\text {th }}$ & $2.21^{\mathrm{a}}$ & $2.06^{\mathrm{b}}$ & $2.18^{\mathrm{a}}$ & 0.007 & **** \\
\hline & $15^{\text {th }}$ & 98.08 & 100 & 100 & 0.641 & NS \\
\hline \multirow[t]{3}{*}{ Liveability (\%) } & 23th & 98.08 & 98.08 & 100 & 0.907 & NS \\
\hline & $28^{\text {th }}$ & 96.15 & 98.08 & 96.15 & 1.228 & NS \\
\hline & $35^{\text {th }}$ & 94.23 & 98.08 & 94.23 & 1.109 & NS \\
\hline
\end{tabular}

Data represent mean values of four replicate groups consisting of 13 birds per replicate during d1-35 days; abcMeans bearing uncommon superscripts in a row are significantly different at $* * * \mathrm{P}<0.001$; SEM $=\mathrm{Standard}$ error of mean; NS=Non-Significant.

\section{Feed intake}

Feed intake upto 23th, 28th and 35th days of age was affected $(\mathrm{P}<0.001)$ by the strains, except for $15^{\text {th }}$ day of age. Feed intake at $15^{\text {th }}$ day only was found to be similar $(\mathrm{P}>0.001)$ between the treatment groups of birds. Feed intakes of Hubbard classic, Cobb-500 and MPK broiler strains were $2955.4 \mathrm{~g}, 2855.4 \mathrm{~g}$ and $2783.0 \mathrm{~g}$ per bird, respectively, at $35^{\text {th }}$ day of age. On day 28th, significantly $(\mathrm{P}<0.001)$ the highest feed intake (1580.55g) was observed in Cobb-500 broiler strain followed by 1560.38g, 1475g in Hubbard classic and MPK broiler strains, respectively. At $35^{\text {th }}$ day, bird of $T_{1}$ (Hubbard) group was the highest $(\mathrm{P}<0.001)$ in feed intake, while birds of $\mathrm{T}_{3}$ (MPK) group being the lowest in feed consumption. The feed intake of $T_{1}$ strain group was similar to the strain of Cobb-500, but differed significantly $(\mathrm{P}<0.001)$ from the other strain (MPK) during $35^{\text {th }}$ day of age.

\section{Feed conversion ratio (FCR)}

Feed conversion ratio (FCR) was influenced $(\mathrm{P}<0.001)$ by strains from 23th to $35^{\text {th }}$ days of age. FCR, only during the $15^{\text {th }}$ days of age did not differ significantly $(\mathrm{P}>0.001)$, which showed nonsignificant differences between the treatment group of birds. At $35^{\text {th }}$ day of age, statistically similar but significantly higher FCR values (2.21;
2.18) were found in the birds of Hubbard classic and MPK broiler strains, while significantly lowest $(\mathrm{P}<0.001)$ FCR value $(2.06)$ was observed in Cobb-500 broiler strains. The lowest figure of FCR indicates that birds of this strain (Cobb500) are supposed to be more efficient in converting feed to meat than others.

\section{Liveability (\%)}

In the present study, the liveability (\%) of three broiler strains during the experimental period (35th day) were $94.23 \%, 98.08 \%$ and $94.23 \%$ in Hubbard Classic, Cobb-500 and MPK broiler strains, respectively (Table 2). Liveability of the three strains throughout the entire rearing period (15th to 35th days) did not show any significant $(\mathrm{P}>0.001)$ difference between the treatment groups.

\section{Cost benefit analysis}

The data on cost of production of three broiler strains at 35 days of age are shown in Table 3. Higher $(\mathrm{P}<0.001)$ live weight was found in the $\mathrm{T}_{2}$ (Cobb-500) group, while $\mathrm{T}_{3}$ (MPK) group of birds being the least. Apart from live weight, no other significant difference was found in the remaining data presented in this Table 3. Despite insignificant effect, numerically higher feed cost was found in $\mathrm{T}_{1}$ (Hubbard classic) and $\mathrm{T}_{3}$ (MPK) broiler groups, respectively. Total cost of 
production (1.24 dollar/ kg live bird) was less for other strain groups $\left(\mathrm{T}_{1}\right.$ and $\left.\mathrm{T}_{2}\right)$. Lowest cost $\mathrm{T}_{2}$ (Cobb-500) group and net profit (0.21 dollar/ kg benefit ratio (5.9:1) was also found in $\mathrm{T}_{2}$ (Cobblive bird) was found higher in this strain than the 500) group.

Table 3. Cost benefit analysis at the end of the trial period (35 days)

\begin{tabular}{|c|c|c|c|c|}
\hline & \multicolumn{3}{|c|}{ Treatments } & \multirow{2}{*}{$\begin{array}{l}\text { Level of } \\
\text { significance }\end{array}$} \\
\hline & $\begin{array}{l}\mathrm{T}_{1}(\mathrm{Hubbard} \\
\text { classic) }\end{array}$ & $\mathrm{T}_{2}(\mathrm{Cobb}-500)$ & $\left.\mathrm{T}_{3}(\mathrm{MPK})\right)$ & \\
\hline Live weight(g/bird) & $1375.8^{\mathrm{b}} \pm 16.4$ & $1425.3^{a}+20.6$ & $1315^{c} \pm 4.2$ & *** \\
\hline Feed cost (dollar/ kg) & 0.78 & 0.73 & 0.77 & NS \\
\hline Chick cost (dollar/bird) & 0.51 & 0.49 & 0.49 & NS \\
\hline${ }^{1}$ Other cost (dollar/ kg) & 0.18 & 0.18 & 0.19 & NS \\
\hline Market price (dollar/ kg live weight) & 1.45 & 1.45 & 1.45 & NS \\
\hline $\begin{array}{l}\text { Total cost of production } \\
\text { (dollar/ kg live broiler) }\end{array}$ & 1.33 & 1.24 & 1.34 & NS \\
\hline Net profit(dollar/kg live weight) & 0.12 & 0.21 & 0.11 & NS \\
\hline Cost: Benefit Ratio & 11.08 & 5.90 & 12.18 & NS \\
\hline
\end{tabular}

Data (live weight) represent mean values of four replicate groups consisting of 13 birds per replicate at 35 days; The rest of the data represent here manually calculated figure (mean values); \# Values indicate mean \pm SD; abcMeans bearing uncommon superscripts in a row are significantly different at $* * * P<0.001$; NS=Non-Significant. 1Other costs include vaccination, medication \& disinfectant, litter, labour, water \& electricity and transport cost; Currency considered here US dollar by converting local taka as per the equivalent values allow during the experimental period.

\section{Discussions}

\section{Growth performance (live weight and live weight gain)}

Traditionally, the salient criteria for appraising the performance of the broiler strains have been growth rate and feed conversion efficiency, and less frequently, carcass composition (Cahaner et al., 1987; Cabel \& Waldroup, 1991; Smith \& Pesti, 1998; Rezaei et al., 2004), but some strains may show higher mortalities and a great variation in final body weight than others due to several factors (strains, sex, feed, disease incidences, environmental condition and so on). Chicken growth is well described as a sigmoid curve with an initial exponential development phase, and a final phase of inhibited growth that consists of gradual reduction in the growth rate following an asymptotic increase in the body weight (Aguilar et al., 1983). However, the duration of this experiment was only to complete the first phase of growth which is the initial exponential development phase, because the phases afterwards are not economic for broiler producers.

However, significant differences were observed in the live weight and average body weight gain among the three broiler strains rearing under the farming conditions of Bangladesh in this present study. Cobb-500 broiler strain achieved heavier body weight and higher weight gain than the other strains. The improved body weight gain of this strain, possibly due to higher feed intake and several other factors might be involved herewith. Our results are in agreement with the reports of several other previous researchers (Gonzales et al., 1998; Sarker et al., 2001 \& 2002; Abdullah et al., 2010), who found similar variations in rearing different strains under experimental conditions. The differences of the live weight and weight gain of the broiler strains may be explained by different factors, for example, genotype, feed, sex, strains, environmental conditions, climatic effects and so on. Gonzales et al. (1998) found strain effects among several strains of birds in live weight. Korver et al. (2004) reported that genotype may affect the body weight of different broiler strains. Genetic variation of the strains amongst other factors might give rise to body weight variation between two individual birds. So it is assumed that more weight gain of Cobb500 broiler strain might arise from the genetic make-up during the embryonic stage, which can lead to having different growth potential, and it may be possible owing to the strain effect, and some other factors might be involved herewith.

\section{Feed intake}

The ingestion of the optimal level of dietary nutrients, whether for birds involved in egg or meat production, is very much dependent on the level of feed intake. The complexities of the factors which determine nutrient intakes and causative reasons and hypotheses for under or over consumption, have been reviewed extensively by many former researchers (Forbes, 1995; Van der Heide et al., 1999; Forbes, 2006). Birds have precise requirements for nutrients, both macro and micro, and energy-yielding components. Therefore, knowledge of their feedintake capacity is essential if dietary concentrations are to be appropriate. A bird's daily consumption of feed ultimately governs its health, development and potential for reproduction. 
However, feed consumption of Cobb-500 broiler strain corresponding to Hubbard classic was found to be higher than other strain in this study. The higher feed consumption of the strains may be resulted from the heavier body weight and individual body requirements of the birds. In addition, the reason for higher feed intake may be explained by several other factors including breed or strain, feed quality, palatability of feed, age, sex, individual body requirement, stage of production, climatic effect and other environmental conditions. Smith et al. (1998) reported that strain and sex can affect feed intake and feed conversion ratio. Goliomytis et al. (2003) reported that feed intake was comparable between Cobb-500 and shaver Starbro strains through 154 days of age. They reported that feed intake of broilers increased until 84 days of age and then declined until 112 days of age. Our findings are in agreement with their results, as our experiment was ended at 35 days and there was also a continuous increase in feed intake.

However, in contrast, the poor performance and reduced feed intake of the broiler strain (MPK) may be affected by the adverse environmental impact. This strain is supposed to be less heattolerant than others, which might affect their feed consumption capacity and other performance as well. Baghel and Pradhan (1989) and Islam (2000) reported that broiler performance is reduced significantly when they are raised under hot-humid and dry seasons than the cold-climatic condition.

\section{Feed conversion ratio (FCR)}

Feed conversion ratio (FCR) of the Cobb-500 broiler strain was found to be superior to other strains in this study. This performance might be partly due to the capacity of this strain (Cobb$500)$ to consume greater quantities of feed, resulting in higher intakes and hence greater live weight, weight gain and improved FCR than in other broiler strains. The improved FCR of Cobb500 birds indicates that this strain is more efficient in converting feed to meat more rapidly than in other strains. Our findings are in agreement with the report of Abdullah et al. (2010) who found similar FCR value in Hubbard classic strain of broiler during the rearing period from 7-42 days of age. Gonzales et al. (1998) also reported that FCR value may be differed due to the interaction of genotype amongst the strains, and found the highest FCR values in several strains including Hubbard classic strain of broilers. FCR values of this study indicated that improved feed efficiency showed by Cobb-500 broiler strains, then inferior trend of FCR values was followed by Hubbard classic and MPK strains subsequently at $35^{\text {th }}$ days of age.

\section{Liveability}

The liveability (\%) of the broiler strains was unaffected by all the treatment groups throughout the trial period (d 1-35). Birds of Hubbard classic and MPK strains grew poorly than the Cobb-500 birds, even though the liveability (\%) of these two strain group of birds were identical during the $35^{\text {th }}$ days of age. It may, therefore, be deduced that strains did not adversely affect the bird liveability. So to say, the effect of strain on the liveability (\%) of broiler chickens is exiguous or nominal. The current findings are in agreement with that of Sarker et al. (2001 \& 2002) who demonstrated that strains had no adverse effect on liveability of the birds. Despite this non-significant effect, numerically higher liveability was observed in Cobb-500 strain group, followed by Hubbard and MPK, respectively.

\section{Cost benefit analysis}

Higher net profit and lower cost benefit ratio were observed in the Cobb-500 broiler strain than in other strains despite the non-significant effects between the treatments. The reason behind this is possibly due to attaining heavier body weight and lower production cost than in other strains. In addition, higher liveability of this strain (Cobb-500) might influence higher net profit than in other strains. Higher profit margin was obtained by the farmers by selling these birds in the market on the live weight basis, as this strain (Cobb-500) attained heavier body weight than in other strains in this study.

\section{Conclusion}

It can be concluded that Cobb-500 broiler strain has supported comparatively better growth responses in terms of body weight, feed efficiency, net profit and lower cost of production than those of Hubbard classic and MPK strains. So, Cobb-500 broiler strain may be recommended as economic and more suitable for rearing under the farming management in Bangladesh.

\section{References}

Abdullah, Y., Abdullah, Nafez A. Al-Beitawi, Murad M.S. Rjoup, Rasha I. Qudsieh and Majdi A.A. Ishmais. 2010. Growth Performance, Carcass and Meat Quality Characteristics of Different Commercial Crosses of Broiler Strains of Chicken. J. Poultry. Sci., 47: 13-21.

Aguilar, C., Friedli, C., and Canas, R. 1983. The growth curve of animals. Agric. Systems, 10: 133-147.

Baghel, R.P.S. and Pradhan, K. 1989. Performance of broilers influenced by the phase of growth and seasons. Indian Vet. J., 66: 1176-1178. 
Bogdangnov, G.A. 1990. Feeding of Farm Animals: 105-494, Russia.

Bohren, B.B., Rogler, J.C. and Carson, J.R. 1982. Survival under heat stress of lines selected for fast and slow growth at two temperatures, Poultry Science, 61: 1804-1808.

Cabel, M.C. and Waldroup, P.W. 1991. Effect of dietary protein level and length of feeding on performance and abdominal fat content of broiler chickens. Poultry Science, 70: 15501558.

Cahaner, A., Dunnington, E.A., Jones, D.E., Cherry, J .A. and Siegel, P.B. 1987. Evaluation of two commercial broiler lines differing in efficiency of feed utilization. Poultry Science, 66: 1101-1110.

FAO. 2006. Responding to the livestock revolution-the case for livestock public policies. Livestock Policy Brief 01.Livestock Information, Sector Analysis and Policy Branch, animal Production And Health Division, Food and Agriculture Organization of the United Nations, Rome.

Farran, M.T., Khalil, R. F., Uwayjan, M.G. and Ashkarian, V.M. 2000. Performance and carcass quality of commercial broiler strains. J. Appl. Poultry Res., 9: 252-257.

Forbes J.M. 2006. Food choice and intake in chickens. In V. Bels, ed. Feeding in domestic vertebrates from structure to behaviour, pp. 108-119. Wallingford, UK, CABI.

Forbes, J.M. 1995.Voluntary feed intake and diet selection in farm animals. Wellington, UK, CABI.

Goliomytis, M., Panopoulou, E. and Rogdakis, E. 2003. Growth curves for body weight and major component parts, feed consumption, and mortality of male broiler chickens raised to maturity. Poultry Science, 82: 1061-1068.

Gonzales, E., Johan, B., Takita, T.S., Sartori, J.R. and Decuypere, E. 1998. Metabolic disturbances in male broilers of different strains. 1. Performance, mortality, and right ventricular hypertrophy. Poultry Science, 77: 1646-1653.

Hossain, M. A, Chowdhury, S.D., Roy, B.C., Miazi, O.F. and Islam, M.M. 2008. Chemical evaluation of broiler feed (pellet) received from different feed mills in Bangladesh. Int. J. Sust. Agril. Tech., 4(1): 5-11.

Islam, M.A. 2000. Effect of local and exotic strains of chicken at hot-humid climate. In: Ph.D Thesis, Institute of Animal Science, Faculty of Agriculture and Horticulture, Humboldt University of Berlin, Germany.

Korver, D.R., Zuidhof, M.J. and Lawes, K.R. 2004. Performance characteristics and economic comparison of broiler chickens fed wheat-and triticale-based diets. Poultry Science, 83: 716-725.
Latif, M.A. 1998. Broiler Utpadan (Production). Bangla Academy Publishers, Dhaka, Bangladesh. pp. 24-35.

Latif, M.A. 1999. History of Poultry Industry in Bangladesh. Proc. of the seminar of Int. Poultry Show, WPSA. Bangladesh Branch. pp. 11-17.

Minitab. 2010. Minitab Statistical Software User's Guide 2: Data Analysis and Quality Tools. Minitab Release 16. Minitab Inc., State College, PA 16801-3008, USA.

NRC(National Research Council). 1994. Nutrient Requirements of Poultry. 8th Rev.Edition. National. Academy Press, Washington, DC.

Rezaei, M. Nassiri, H., Moghaddam, Pour Reza, J . and Kermanshahi, H. 2004. The effect of dietary protein and lysine levels on broiler performance, and carcass characteristics and N. Excretion. Int. J . Poultry Sci., 3(2): 148-152.

Roy, B.C., Ranvig, H., Chowdhury, S.D., Rashid, M.M. and Chwalibog, A. 2004. Evaluation of compound broiler feeds manufactured in Bangladesh. Livestock Res. Rural Dev. 16(11): 1-8.

Sarker, M.S.K., Ahmed, S.U., Chowdhury, S.D., Hamid, M.A. and Rahman, M.M. 2001. Performance of different fast growing broiler strains in Winter, Pakistan J. Biol. Sci., 4(3): 251-2001.

Sarker, M.S.K., Islam, M.A., Ahmed, S.U. and Alam, J. 2002. Profitability and meat yield traits of different fast growing broiler strains in Winter. Online J. Biol. Sci., 2(6): 361-363.

Smith, E.R, Pesti, G.M, Bakalli, R.I., Ware, G.O. and Menten, J.F. 1998. Further studies on the influence of genotype and dietary protein on the performance of broilers. Poultry Science, 77: 1678-1687.

Smith, E.R. and Pesti, G.M. 1998. Influence of broiler strain cross and dietary protein on the performance of broilers. Poultry Science, 77: 276-281.

Steinfeld, H., Gerber, P., Wassenaar, T., Castel, V., Rosales, M. and de Haan, C. 2006. Livestock's Long Shadow: Environmental issues and options. Chapter 2. Rome: Food and Agriculture Organization of the United Nations.http:/ / www.fao.org/ docrep/ 010/a 0701e/a0701e00.HTM.

Van der Heide, D., Huisman, E.A., Kanis, E., Osse, J.W.H. and Verstegen, M.W.A. 1999. Regulation of feed intake. Wallingford, UK, CABI Publishing. 